\title{
Níveis de Compreensão de Termos para Espécies Naturais
}

\author{
Adriana Silva Graça
}

No seu ensaio "Understanding, context-relativity, and Description Theory", Jason Stanley i)- apresenta uma caraterização da Teoria Descritivista de termos para espécies naturais, ii)- apresenta os argumentos que, do seu ponto de vista, são relevantes na argumentação de Putnam ${ }^{2}$ contra aquela teoria, e iii)- propõe uma refutação do argumento de Putnam, reavivando desta forma a defesa de uma Teoria de tipo Descritivista para aquele tipo de termos (urna vez que se considera, com Devitt ${ }^{3}$, que o argumento de Putnain é o mais forte contra aquela teoria). O seu resultado é importante dado que obtem igualmente para o caso de nomes próprios, pretendendo então reavivar a Teoria Descritivista em geral ${ }^{4}$.

Neste ensaio, o meu objectivo é mostrar que a crítica de Stanley é improcedente, em particular que o argumento de Putman, naqueles aspectos considerados por Stanley, é válido. Logo, se assim for, a Teoria Descritivista de termos para espécies naturais é incorrecta. Começo por sistematizar os passos cruciais do argumento de Stanley, seguindo a ordem i)- a iii)- acima mencionada, para de seguida argumentar a favor da procedência do argumento de Putnam.

\section{Caracterização de uma Teoria Descritivista para termos de espécies naturais}

Uma Teoria Descritivista de termos para espécies naturais define-se como sendo aquela que dá uma resposta unificada a dois problemas filosóficos diferentes, o problema da fixação da referência e o da compreensão individual. A Teoria Descritivista caracteriza-se assim pela defesa da seguinte conjunção de teses:

Tese A: Termos para espécies naturais referem o objecto que referem em virtude de ao seu uso estar associado um conjunto de propriedades, as quais são verdadeiras do objecto; que é então dito ser a referência do termo.

Note-se que o conjunto de propriedades ${ }^{5}$ em causa proporciona a(s) propriedade(s) identificadora(s) do objecto que é a referência do termo e que a Tese A

J. Stanley, 1999. "Context-Relativity and the Description Theory". Analysis 59: 14-18.

2 H. Putnam, 1989. "The Meaning of Meaning", in his Mind, Language and Reality: Philosophical Papers, Volume 2, 215-271. Cambrige, Cambrige University Press.

3 M. Devitt and K. Sterelny, 1987. Language and Reality. Cambrige: MIT Press, p. 46.

4 Cf. J. Stanley, Ibidem, p. 15.

5 Este conjunto pode ser interpretado de diversas formas, de acordo com o tipo de Teoria Descritivista considerada. 
responde assim ao problema da fixação da referência de um termo para espécies naturais. A referência é encontrada em virtude de um conjunto de predicados ser satisfeito univocamente por parte de um objecto.

Tese B: Para compreender um termo para espécies naturais, tem que se saber qual o conjunto de propriedades que fixam a sua referência.

Note-se que a Tese B responde ao problema da compreensão de um termo para espécies naturais: comprendê-lo consiste em saber que um certo conjunto de propriedades (aquelas que fixam a referência do termo) são atribuíveis com verdade ao objecto. O que uma pessoa tem que saber, para compreender um termo, envolve então os predicados por meio dos quais a identificação do objecto (que o termo supostamente refere) é feita.

A principal consequência de aceitar a Teoria Descritivista é então a de aceitar a tese, que podemos designar por Tese $(*)$, segundo a qual

TESE $(*)$ : Para compreender um termo é necessário existir conhecimento identificador (informativo ou não-trivial) do objecto que o termo refere.

Isto significa que a não existência de conhecimento identificador acerca do objecto que é a referência do termo implica ipso facto a não compreensão desse termo, ou, por outras palavras, a compreensão de um termo requer a existência do conhecimento identificador por meio do qual se identifica o objecto que é a sua referência.

\section{Argumentos de Putnam contra a Teoria Descritivista de termos para espécies naturais}

Putnam, contra a teoria atrás apresentada, argumenta da seguinte forma:

TESE (CONTRA*): É possível existir compreensão de um termo para espécies naturais sem que exista informação que seja suficiente para fixar a referência desse termo, i.e., sem que exista conhecimento identificador do objecto que é a sua referência.

O caso dos termos 'olmo' e 'faia', entre os diferentes casos apresentados por Putnam, é aquele que é considerado por Stanley ${ }^{6}$. O argumento de Putnam consiste em mostrar que um utente "médio"7 da língua, que compreende os dois termos, tem uma informação insuficiente para individuar a referência de cada um deles. Logo, contra o que afirma a Teoria Descritivista, para haver compreensão de um termo não é exigível estar-se na posse de conhecimento identificador da sua referência ou da sua extensão. É de facto possível, se Putnam tiver razão (como eu penso que ele tem), estar-se numa situação em que se compreende um termo sem que isso signifique estar-se na posse de toda a informação que é necessária para identificar univocamente o objecto que a satisfaz.

\section{Refutação de Stanley do argumento de Putnam e consequente aceitação da Teoria Descritivista de termos para espécies naturais}

6 Apesar de os exemplos de Putnam serem diversos. O argumento da Terra Gémea visa obter o mesmo resultado.

7 Entenda-se, um utente não-perito, i.e., aquele que não tem meios para distinguir um olmo de uma faia, ou para determinar que água é $\mathrm{H}_{2} \mathrm{O}$. 
Contra Putnam, Stanley defende a Teoria Descritivista afirmando, basicamente, que a compreensão é um conceito sensivel ao contexto e, assim sendo, relativamente a um utente médio do termo, em particular de um termo para espécies naturais,

1. que só é possível dizer-se que se compreende o termo 'olmo' em alguns, mas não em todos, os contextos nos quais o termo é usado.

2. Logo, que há contextos nos quais a incompreensão associada ao uso do termo impede o falante de compreender do que se está a falar.

3. e, finalmente, que assim sendo, existe um nível de compreensão - o da compreensão total - no qual a Teoria Descritivista é correcta: só compreende (completamente) o termo aquele que tem possibilidade de identificar a sua referência inequivocamente.

Obviamente, subjacente a estas críticas está a ideia, com a qual concordo, segundo a qual existe compreensão total de um termo (por parte de alguém) se e somente se existe compreensão em todos os contextos nos quais o termo é usado (por parte desse alguém). Stanley estabelece então que, dado que o conceito de 'compreensão' pode ser caracterizado em diferentes graus, Putnam não mostrou que tem compreensão completa do termo 'olmo' e, ao mesmo tempo, que não tem conhecimento identificador que lhe permita fixar a extensão de 'olmo'. Putnam simplesmente tem uma compreensão parcial de 'olmo'. Nas palavras de Stanley, “A compreensão total, compreensão em todos os contextos, requer o tipo de conhecimento exigido pela Teoria Descritivista"8. E logo, se assim o é, o argumento anti-descritivista de Putnam falha.

Note-se que a parte construtiva do ensaio de Stanley opõe assim, ao argumento atribuido a Putnam, uma teoria de níveis de compreensão de termos para espécies naturais, reavivando assim, neste contexto, a teoria tradicional de tipo descritivista para este género de termos, nomeadamente mostrando que a compreensão total de um termo requer efectivamente estar-se na posse de conhecimento identificador da sua extensão.

\section{Improcedência da crítica de Stanley}

Passo agora a mostrar porque é que a crítica de Stanley é improcedente. Vou dividir o meu argumento em dois, de facto. O primeiro lança luz sobre o que é necessário e suficiente para refutar a Teoria Descritivista, tirando daí as devidas consequências no que respeita à improcedência do argumento de Stanley atrás apresentado; o segundo, mostra que em "The Meaning of Meaning" Putnam desenvolve justamente uma teoria de níveis de compreensão de termos para espécies naturais, a qual é consistente com o seu argumento anti-descritivista, não servindo assim para o refutar.

Por outras palavras, penso que o argumento de Stanley só seria válido se fosse dirigido a um argumento anti-descritivista que não é aquele que Putnam efectivamente tem. Vou assim mostrar, em primeiro lugar, que Putnam não tem o argumento anti-descritivista que lhe é atribuido por Stanley porque não precisa de um argumento tão forte quanto esse para atingir o seu objectivo; um argumento consideravelmente mais fraco é suficiente para refutar o descritivismo. Em segundo lugar mostrarei, agora pela positiva, que o argumento anti-descritivista de Putnam, por seu turno, incorpora uma teoria de níveis de compreensão de termos para espécies naturais, teoria esta, alegadamente, introduzida por Stanley ${ }^{9}$ para o efeito de refutar Putnam. Uma teoria de níveis de compreensão de termos para espécies naturais é, efectivamente, usada por Putnam como parte da sua refutação do Descritivismo.

9 Stanley atribui a autoria de uma teoria deste tipo a M. Dummett e a J. Higginbotham. 


\section{a) Improcedência - Parte I}

$\mathrm{O}$ argumento de Putnam constitui um ataque à Teoria Descritivista, por responder a um problema conhecido na literatura filosófica como o problema da ignorância o qual (em conjunto com o problema do erro ${ }^{10}$ ) constitui o problema básico que qualquer Teoria Descritivista tem que enfrentar.

O problema da ignorância consiste em constatar que, muitas vezes no decorrer da comunicação em comunidades linguísticas, a compreensão que as pessoas têm dos termos que usam é insuficiente - porque as pessoas estão num certo grau de estado de ignorância acerca das propriedades identificadoras do objecto que é a referência dos termos - para determinar univocamente a extensão desses termos. O problema do erro consiste em constatar que essa informação (ou conhecimento identificador) do objecto que lhe está associada, pode ser incorrecta (pode ser falsa acerca do objecto), sem que os utentes deixem de refir o objecto que é a extensão desse termo, quando o usam, e sem que os utentes revelem incompetência no uso do termo ${ }^{11}$. Os dois problemas são sintomas com uma e a mesma causa, o que permite a um anti-descritivista concluir:

TESE (CONTRA*): Não é exigível, para a compreensão de um termo, estar-se na posse do conhecimento identificador do objecto que é a sua referência, ou, por outras palavras, de toda a informação relevante que torna possível proceder-se à identificação unívoca do objecto.

Concentramo-nos agora no problema da ignorância, que é aquele que Putnam e Stanley consideram. Do ponto de vista de Putnam, não é correcto exigir a posse de conhecimento identificador do objecto que um termo refere, por parte de alguém, para se poder usar com compreensão esse mesmo termo, ou seja, é possível que exista, por parte da pessoa em causa, compreensão sem que exista aquele conhecimento. É isto que o exemplo do olmo e da faia mostra: há compreensão dos dois conceitos sem haver conhecimento identificador que permita descriminar cada um dos objectos.

O primeiro aspecto a notar, então, é que Putnam não alega que a sua compreensão do termo 'olmo' corresponda a uma completa ou total compreensão dele. Se este é o caso, Putnam poderia subscrever as afirmações 1 a 3 de Stanley, sem que isso afectasse a procedência do seu argumento anti-descritivista: de facto, como Stanley bem observa, 1) a sua (de Putnam) compreensão do termo 'olmo' é parcial, 2) há contextos nos quais a parcialidade da sua (de Putnam) compreensão impede que ele siga uma conversa sobre olmos e, 3) se existisse da sua (de Putnam) parte uma compreensão total de 'olmo' então ela seria suficiente para fixar a referência do termo ${ }^{12}$. Segue-se assim que o argumento de Stanley não atinge o ponto de Putnam, donde resulta a improcedência do seu argumento. Efectivamente, para o argumento de Putnam ser válido, não é preciso exigir compreensão completa ou compreensão em todos os contextos. ensaio:

Regressemos à tese fulcral da Teoria Descritivista apresentada no início deste

TESE $\left({ }^{*}\right)$ : Para compreender um termo é necessário existir conhecimento identificador do objecto que o termo refere.

10 Enfrentado por S. Kripke, (1990). Naming and Necessity. Cambridge: Harvard University Press, no que respeita a nomes próprios.

11 Como Putnam bem nota, esta situação é impossível para termos de espécies naturais como 'olmo', 'água' ou 'tigre': não é possivel usar qualquer um destes termos competentemente sem se ter bastante informação acerca da sua extensão (cf. H. Putnam, Ibidem, p. 247).

12 Apesar de, mesmo assim, não ser suficiente para dar o seu sentido. Este aspecto é fundamental na argumentação anti-descritivista, mas não o vamos aqui desenvolver, por ele ser irrelevante para a argumentação contida neste ensaio. 
A condição necessária identificada para a compreensão de qualquer termo (por parte de alguém) é a de se estar na posse de conhecimento identificador do objecto que é dito ser a referência do termo. Para esta teoria, não há graus de compreensão, ou seja, não há o conceito de compreensão relativa a um certo contexto: um termo ou se compreende, ou não se compreende, sendo que a condição especificada acima tem que ser satisfeita para se poder dizer que alguém o compreendeu. E a condição exige muito, ou seja, exige, por parte do falante, conhecimento identificador (informação suficiente para) para se determinar o objecto que univocamente o satisfaz. Se um utente da língua não estiver na posse deste conhecimento, então ele não compreendeu o termo. Para refutar esta tese, de natureza universal, Putnam só precisa naturalmente de mostrar que ela não é universal. Efectivamente é isso que ele faz. Putnam mostra unicamente que $h a ́$ contextos nos quais existe compreensão sem que exista conhecimento identificador do objecto, e isto é quanto basta para refutar o Descritivismo.

De facto Putnam não precisa de mostrar que o utente em causa compreende o termo em todos os contextos para refutar o Descritivismo. Tudo depende, na verdade, da forma como se define uma Teoria Descritivista: i) - como exigindo, apenas para alguns contextos do uso de um termo por parte de uma pessoa, conhecimento identificador do objecto, para se poder dizer que a pessoa compreende o termo ou ii) - como exigindo, para todos os contextos de uso do termo por parte de uma pessoa, conhecimento identificador do objecto, para se poder dizer que a pessoa compreende o termo. Putnam, como qualquer anti-descritivista, só teria que defender a tese de, em todo o contexto do uso de um termo, compreeder o termo, sem a correspondente existência de conhecimento identificador do objecto que é a sua referência, supondo a primeira hipótese como correcta. Mas esta não é a hipótese correcta, nem sequer para o próprio Stanley - o que é notório na formulação $(*)$. Logo, para opôr à segunda hipótese de encarar o Descritivismo, Putnam só precisa de mostrar que há contextos nos quais existe compreensão de um termo sem que exista o suposto conhecimento identificador do objecto correspondente, para como isso atingir o seu objectivo.

O objectivo geral contra o Descritivismo fica executado quando se mostrar que ela não é uma teoria universal, pelo que basta mostrar que há casos nos quais ela não é eficaz.

\section{b) Improcedência - Parte II}

O resultado até agora estabelecido não mostra que, apesar de Putnam não argumentar (porque não precisa disso para efeitos de estabelecer o seu argumento) que em todo o contexto de uso do termo 'olmo' existe compreensão sem que exista conhecimento identificador, efectivamente não o faça. Passamos agora a mostrar que este não é o caso.

Comecemos pelo terceiro aspecto salientado por Stanley, com o qual ele pretende refutar o argumento de Putnam, mas que considero que Putnam ele próprio subscreveria:

Existe um nível de compreensão - a da compreensão total - no qual só compreende o termo aquele que tem possibilidade de identificar a sua referência inequivocamente, i.e., se, por parte de alguém, existe uma compreensão total de 'olmo' então esse alguém está na posse de informação suficiente para fixar a referência do termo.

As ideias contidas em "The Meaning of Meaning"13 não só acomodam sem dificuldade este resultado como o sugerem explicitamente. A ideia crucial deste ensaio,

13 Cf. H. Putnam, Ibidem, pp. 227-29 e 245-52 onde, respectivamente, se trata do Princípio da Divisão Universal do Trabalho Linguístico e dos conceitos de 'estereotipo' e 'definição operacional'. 
na qual se propõe uma nova elucidação do conceito de 'sentido', é a seguinte. Há duas formas de elucidar o sentido de um termo para espécies naturais: por meio de uma definição ostensiva ou por meio de uma definição operacional. Pela primeira, mostra-se a contribuição do próprio objecto para a elucidação do sentido do termo que o designa, pela segunda, mostra-se a contribuição da sociedade para esta mesma elucidação. Há dois elementos que contribuem complementarmente para a elucidação do sentido de um termo para espécies naturais: o próprio objecto referido e a sociedade. É no desenvolvimento do segundo destes dois elementos que podemos encontrar as ideias que tornam o argumento de Stanley improcedente.

A fixação da referência para termos de espécies naturais, termos os quais com o desenvolvimento da ciência estão sujeitos à divisão do trabalho linguístico, não é feita individualmente excepto no caso do subconjunto dos falantes que estão em condições de o fazer, aqueles a que Putnam chama 'peritos'. Só estes têm uma compreensão total - ou em todos os contextos do seu uso - do termo. O utente "médio" deste tipo de termos não está em condições de, individualmente, fixar a sua referência. Por exemplo, não distingue um olmo de uma faia (dado que a informação que tem acerca de um destes tipos de árvore coincide com a informação que tem acerca do outro), nem água de um líquido que lhe é fenomenicamente idêntico mas não é $\mathrm{H}_{2} \mathrm{O}$, nem um tigre de um robot hipercomplexo em tudo igual ao tigre mas sem a sua estrutura genética (que não é um tigre), nem um limão de um objecto de silicone com a aparência de um limão, sem o ser, nem o ouro de um metal amarelo que parece ouro mas que não tem o número atómico 79 , e logo não é ouro. Só a comunidade linguística no seu conjunto, baseada no conhecimento de peritos, o pode fazer.

A incapacidade individual mencionada manifesta-se também de outra forma. O utente "médio" de termos para espécies naturais também não está em condições de identificar um olmo que tem uma malformação e que por essa razão tem características que já não correspondem à informação vaga que ele tem acerca deste tipo de árvores. O mesmo se aplica a limões que não são amarelos ou não têm gosto amargo, a tigres que não têm listas pretas, a ouro com outra cor, a água que por qualquer razão tem sabor, ou a um gato com alguma malformação congénita de tal ordem que faça com que ele já não pareça um gato.

A dupla manifestação da incompetência individual para fixar a referência deste tipo de termos resulta do facto de a definição operacional de cada um deles conter aquela informação mínima necessária para se fazer parte de uma dada comunidade linguística, e ser-se considerado competente no uso da língua, mas não conter informação necessária nem suficiente para fixar a referência. O estereotipo associado a cada um dos termos, como Putnam lhe chama, é útil para definir o nível mínimo de competência no uso do termo, mas o seu papel termina aí.

É a teoria de Putnam que contém então ingredientes para fazer as observações de Stanley acerca do termo 'olmo' usado por um utente "médio" da língua. Este manifesta compreensão do termo apenas em alguns contextos de uso ${ }^{14}$. Putnam vai mais longe, e acrescenta ainda que este utente adquiriu apenas parcialmente o termo e esta é a situação em que nos encontramos (e Putnam se encontra) perante o termo 'olmo'. Não ocorre efectivamente compreensão deste tipo de termos em todos os contextos, dado que o utente médio de termos para espécies naturais não está em condições de, individualmente, fixar a sua referência, não tendo conhecimento identificador dela para o fazer. Só a comunidade no seu conjunto, baseada na opinião de peritos, efectivamente o faz.

Mas servem estas considerações para refutar, como Stanley pretende, o argumento anti-descritivista avançado por Putnam? Obviamente, não. O facto de que, em alguns 
contextos do uso de um termo por parte de alguém, existe compreensão do termo sem que exista conhecimento identificador do objecto que é a sua referência, mostra que não se pode exigir, em geral, este conhecimento para que haja compreensão do termo, o que a Teoria Descritivista, como vimos e Stanley reconhece, efectivamente exige. Para esta teoria, a não existência de conhecimento identificador acerca do objecto que é a referência do termo implica ipso facto a não compreensão desse termo. Esta tese, como Putnam mostrou e Stanley não refutou, é então inaceitável.

\section{Referências}

M. Devitt and K. Sterelny, 1987. Language and Reality. Cambrige: MIT Press.

S. Kripke, 1990. Naming and Necessity. Cambridge: Harvard University Press.

H. Putnam, 1989. “The Meaning of Meaning", in his Mind, Language and Reality: Philosophical Papers, Volume 2, 215-271. Cambrige, Cambrige University Press. 14-18.

J. Stanley, 1999. "Context-Relativity and the Description Theory". Analysis 59: 
